\title{
Clean heating and heating poverty: A perspective based on cost-benefit analysis
}

\author{
Tong Feng ${ }^{\mathrm{a}, \mathrm{b}}$, Huibin Du, ${ }^{\mathrm{a},{ }^{*}}, \mathrm{D}^{\prime}$ Maris Coffman ${ }^{\mathrm{b}}$, Aiyu $\mathrm{Qu}^{\mathrm{c}}$, Zhanfeng Dong ${ }^{\mathrm{c}}$

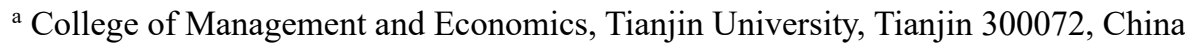 \\ b The Bartlett School of Construction and Project Management, University College London, London, \\ WC1E 7HB, UK \\ ${ }^{\mathrm{c}}$ The Chinese Academy of Environmental Planning, State Environmental Protection Laboratory of \\ Environmental Planning and Policy Simulation, Beijing 100012, China
}

\begin{abstract}
To improve the air quality in winter, clean heating policy was implemented in " $2+26$ " cities of China in 2016, which mainly included replacing coal with gas or electricity. Tremendous financial subsidies have been provided by city and central governments. This new heating mode changed the heating fee-cost to residents. This paper estimates the economic costs to both governments and residents, and evaluates the environmental and public health benefits by combining a difference-in-differences model with an exposure-response function. Results show that the total costs of clean heating were up to 43.1 billion yuan. Governments and residents account for $44 \%$ and $56 \%$ of the total costs, respectively. In terms of benefits, the clean heating project is effective for air pollution control and brings health economic benefits of about 109.85 billion yuan (95\% CI: 22.40-159.83). The clean heating policy was identified as a netpositive benefit program with environmental and public health improvements. However, the inequality in subsidies from different cities governments increases the heating burden on low-income households and leads to heating poverty for households in the less developed regions. We provide suggestions for implementation in future clean heating campaigns and in subsidy mechanism design in China and for other developing countries.
\end{abstract}

\section{Keywords}

Clean heating; Cost-benefit analysis; Heating poverty; Air pollution; Health

\footnotetext{
${ }^{*}$ Corresponding author.

E-mail addresses: duhuibin@tju.edu.cn (H. Du), fengtong@tiu.edu.cn (T. Feng), d.coffman@ucl.ac.uk (D. Coffman), quay@caep.org.cn (A. Qu),dongzf@caep.org.cn (Z. Dong) 


\section{Introduction}

Air pollution in China brings economic and health issues across the country (Sheehan et al., 2014). The average ambient concentrations of particles of less than 2.5 micrometres in diameter $\left(\mathrm{PM}_{2.5}\right)$ in 2013 in 58 Chinese cities were more than double of China's National Ambient Air Quality Standard (NAAQS) of $35 \mu \mathrm{g} / \mathrm{m}^{3}$ and five times the World Health Organization (WHO) annual maximum level (WHO, 2005). In response to this crisis, the Chinese government implemented the "Action Plan for Air Pollution Prevention and Control (2013-2017)", which targeted improving air quality over the five-year period. $\mathrm{PM}_{2.5}$ dropped by $38 \%$ in 2017 compared to the level in 2013 (China, 2013) (Ministry of Ecology and Environment of China, 2013). But there are still 256 cities out of 356 cities whose average annual concentration of $\mathrm{PM}_{2.5}$ exceeded the level of NAAQS (Air Quality Report of Chinses cities, 2017). Air pollution control in China is a long-term challenge and an arduous task. The Chinese government has announced "Plan for Defending the Blue Sky". to ensure greater achievements in air pollution control by setting the target that the annual concentrations of $\mathrm{PM}_{2.5}$ by 2020 will be 18\% lower than that of 2015 (State Council, 2017).

The heating supply in China leads to substantial seasonal increases in the concentrations of pollutants in winter (Qiu J, 2000; Yang et al., 2018). There are two main heating modes in Northern China (Li and Cao, 2017). One is central heating which is operated by local heating stations in cities. The heat generated by the combustion of coal-fired boilers is transmitted to the residents' homes through the heating pipeline. Central heating in China consumes nearly $65 \%$ of building energy consumption and $21 \%$ of total energy consumption (Cui M, 2014). The other heating mode for residents is burning bulk coal with standalone domestic stoves for household heating. In both these two heating modes, combustion of coal in boilers is incomplete, which releases air pollutants, such as suspended particulate matters and $\mathrm{SO}_{2}$, and damages human health (Almond et al., 2009).

To improve the air quality, the "Plan for Air pollution Control in Jing-Jin-Ji and Surrounding Areas" (referred to as the Plan) has been established by the Ministry of Ecology and Environment (MEE) of China and the local governments in June 2016. The plan proposed that " $2+26$ " cities ${ }^{1}$ in Beijing-Tianjin-Hebei (BTH) and surrounding

\footnotetext{
1 " $2+26$ " cities include two municipalities directly under the Central Government which are Beijing and Tianjin, and 26 cities in Hebei, Shanxi, Shandong and Henan provinces.
} 
provinces would be in the first round of implementation of clean heating in winter (MEE, 2016). This plan aimed to help these cities accelerate the clean transformation of heat sources, by focusing on solving the problem of bulk coal combustion. To promote the implementation of clean heating, since 2017 the central government has provided local governments with financial support for the shift to clean heating. The subsidies should be used to speed up the transformation in clean heating source, to solve the problem of bulk coal combustion, to promote the clean transformation of coal-fired boilers and to furnish subsidies for residents. The annual subsidies for municipalities, provincial capitals and prefecture-level cities are 1 billion yuan, 0.7 million yuan and 0.5 billion yuan, respectively (Ministry of Finance of China, 2017). By the end of 2017, about 4.8 million households in the BTH and surrounding regions have switched from coal heating to electricity and natural gas heating. Advanced technology, clean stoves have been widely promoted with the financial supports from governments (Zhang et al., 2019). The central government has provided 19.92 billion yuan in subsidies for clean heating projects through the end of 2018; this figure does not include further subsidies from the local governments (He et al., 2019). Multi-level governments have provided tremendous resources and financial support to facilitate clean heating implementation. Additionally, due to the change of heating mode, the heating fee for residents might also have changed (Pu et al., 2019). To assess the full effects of this policy, we propose the following questions:

What are the economic costs of clean heating for governments at the city level?

What are the economic and health impacts on residents?

On the whole, is clean heating a net benefit or net cost project?

To answer the above questions, this paper evaluates the impact of the clean heating policy on governments and residents and examines the health and economics effects by employing a comprehensive cost-benefit analysis.

It is expected the implementation of clean heating can achieve the environmental and health improvements. First, the traditional coal-fired central heating is harmful for air quality and human health. Compared with Southern China, which does not have central heating, the total suspended particulate and $\mathrm{PM}_{10}$ of Northern China is much higher because of central heating (Almond et al., 2009; Chen et al., 2013; Ebenstein et al., 2017). Central heating also makes the life expectancy 5.5 year lower in the north 
(Ebenstein et al., 2017). Second, clean heating is helpful for air pollution control. He et al. (2019) reported compared in the winter of 2016, concentrations of $\mathrm{PM}_{2.5}$ in winter 2018 dropped by $27.17 \mu \mathrm{g} / \mathrm{m}^{3}\left(109.5 \mu \mathrm{g} / \mathrm{m}^{3}\right.$ to $\left.82.33 \mu \mathrm{g} / \mathrm{m}^{3}\right)$ on average in the " $2+26$ " cities. The decline in coal consumption also produced a drop in air pollutants emissions. Pang et al. (2015) verified that replacing coal with natural gas for central heating is effective for the decline of $\mathrm{CO}_{2}$ and particulate matters emissions. But no previous studies have quantified the effects of clean heating on environment and health. The concentrations of air pollutants are influenced by the meteorological factors, particularly mean temperatures and also levels of precipitation. It is not possible to derive the effects of clean heating on air pollution by comparing the air pollutants of different years.

Clean heating also changes the economic costs to residents. On the one hand, according to the energy ladder, energy use patterns vary with household income (Van et al., 2013). With increases in household income, energy choice changes from biomass fuel to clean energy (Heltberg et al., 2004; Hosier et al., 1987; Leach et al., 1992). On the other hand, changes in energy consumption choice also bring growth in household consumption (Mensah et al., 2015) and lead to significant social disparities across households (Charlier et al., 2018). The low income households are more vulnerable to an excessive energy burden (Agbim et al., 2020). Clean heating changes levels of heating energy consumption for residents. However, the effects of clean heating on residential heating economic costs have not been estimated in previous studies. Hence, a complete and comprehensive evaluation of the effectiveness of clean heating is still missing.

Here, we make a systematic evaluation of the impacts of clean heating on governments and residents of the $2+26$ cities. The associated health and economic benefits and the net benefits of clean heating are also examined in this paper. A comprehensive cost-benefit analysis of clean heating can provide recommendations for the more effective implementation of clean heating in China in the future and also provide guidance for other developing countries.

\section{Methodology}

\subsection{Analytical design}

To implement clean heating, central governments and local governments invest 
huge amounts of money in subsidies for clean heating transformation, such as the equipment subsidy and operation subsidy for natural gas or electric heating. After the government subsidy, the remaining costs of equipment purchase and the changes in heating bills should be borne by residents. Clean energy used for heating also helps reduce air pollutants and benefits human health. In this paper, we calculate the costs and benefits of clean heating policy and analyze its impact on governments and residents.

The analysis includes five steps: difference-in-differences (DID) modeling, direct cost calculation, health and economic effects estimation, net cost-benefit estimation and uncertainty analysis (as shown in Fig. 1.). The first step is the estimation of the number of households which have undergone this transformation in clean heating, mainly including natural gas heating and electric heating. The second step involves the calculation of the direct costs to government and residents for equipment purchase, pipeline installation and operation fees. In the third step, we evaluate the environmental effects of clean heating policy with the DID model. In the fourth step, declines in air pollutants concentrations are inputted into the exposure-response functions from which we get the health and economic benefits. Finally, we examine the net benefits or costs of the clean heating policy and estimate a range of uncertainties and economic values.

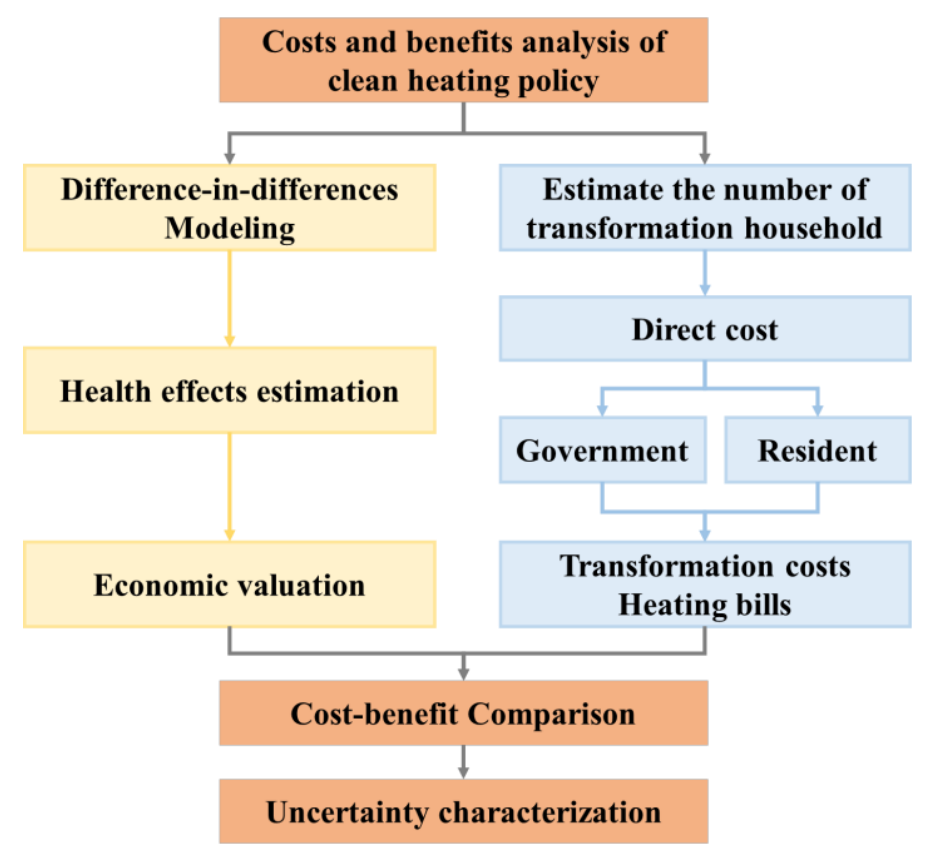

Fig. 1. Analytical sequence of clean heating policy 


\subsection{Costs}

We consider two subjects, governments and residents, for cost analysis. For government, the costs are the subsidy for clean heating and other costs:

$$
C G_{i}=\sum_{t=1} \sum_{j=1}\left(S_{t i j} \times H_{t i j}+C O_{t i j}\right)
$$

where $C G_{i}$ is the costs of governments for clean heating implementation in city $i$ (yuan); $S_{t i j}$ and $H_{t i j}$ denote the subsidy provided by the government and the number of transformation-households, respectively; $C O_{t i j}$ are the other costs for clean heating, such as the cost of central heating transformation and cost of building energy saving. $i$ represents each city of " $2+26$ " city; $j$ represents the clean heating type, including electric heating or natural gas heating; $t$ denotes the period during year 2017 or 2018 . The subsidy for per household provided by the government is calculated by Eq. (2) as following:

$$
S_{t i j}=\left(S E_{t i j}+S P_{t i j}\right) \times \lambda+S O_{t i j}
$$

where $S E_{t i j}$ is the subsidy for each household to purchase equipment; $S P_{t i j}$ represents the subsidy for each household for pipeline network transformation; $\lambda$ is the annual utilization rate, we assume the service life of the equipment and the pipeline is 10 years; $S O_{t i j}$ denotes the subsidy for operation for per household of year $t$. The standards for clean heating subsidies are defined by national and local governments in Beijing, Tianjin and 26 cities in Hebei, Shandong, Shanxi and Henan province.

In addition to the costs borne by governments, residents also spend huge amounts of money on the clean heating transformation. We calculate the costs of residents with Eq. (3):

$$
C R_{i}=\sum_{t=1} \sum_{j=1}\left[\left(C H_{t i j}-S O_{t i j}\right)+\left(C E_{t i j}-S E_{t i j}\right) \times \lambda\right] \times H_{t i j}
$$

where $C R_{i}$ is the cost of residents of city $i ; C H_{t i j}$ is the total cost of heating operation, except for the government's subsidy for operation; the remaining heating operation fees should be paid by the resident. The total cost of equipment purchase $\left(C E_{t i j}\right)$ is paid by both the government $\left(S E_{t i j}\right)$ and the residents; we also calculate the annual utilization 
rate $\lambda$ of equipment cost to residents.

The annual number of households with different types of clean heating transformation and the standard amounts of government subsidy in $2+26$ cities are identified through annual clean heating working plans of each province, and the official news from websites of MEE. We have conducted survey and interviews with the Ecology and Environment Bureaus of $2+26$ cities, and obtained the subsidy standards at city level as supplementary checks.

In our model, the direct cost includes the subsidy provided by governments and the costs of residents. While due to data availability, the indirect cost consists of management costs of governments are not calculated. Because we cannot separate the management costs that are related to clean heating policy from those that are not. Besides, according to the advices from related experts of MEE, the management cost is less than $1 \%$ of the total cost. Hence, we calculated the direct cost of clean heating in our model.

Furtherly, we cite the concept of energy poverty (Douglas, 2018) and employ formula (4) to reflect the economic burden of clean heating on residents:

$$
\text { Ratio of heating } \text { cost }_{i j}=\frac{\text { Heating } \text { cost }_{i j}}{\text { Disposable income }_{i}} \times 100 \%
$$

where Heating cost $_{i j}$ indicates the heating bills of one household in city $i$ for one heating season with the heating mode $j$, including the coal-fired heating, electric heating or natural gas heating. Disposable income $e_{i}$ is the disposable income of one household in city $i$ for one heating season. Based on the definition of energy burden (Guruswamy, 2011), we define households as heating burdened if they spend $4-6 \%$ of their annual income on utility bills, as heating stressed if the ratio of heating cost is $6-10 \%$, as heating poverty if the ratio is more than $10 \%$.

\subsection{Benefits}

The implementation of clean heating helps to reduce the consumption of bulk coal and produces declines in the emissions of air pollutants. Health-economic benefits are produced by the clean heating policy. The benefits calculation comprises three steps: difference-in-differences model, health benefits estimation and economic valuation. 


\subsubsection{Difference-in-differences modeling}

To examine the impacts of clean heating on air quality improvements, we are able to make use of a natural experiment. A difference-in-differences (DID) model is widely used for evaluating the causal effects of a policy (Zhou et al., 2020; Li et al., 2020; Fu and $\mathrm{Gu}, 2017$; Gehrsitz, 2017). We identify the effects of clean heating by comparing the double-differences between the clean heating cities (treatment group) and non-clean heating cities (control group), during both the post-clean heating period and pre-clean heating period. This paper estimates the clean heating effects on $\mathrm{PM}_{2.5}$ concentrations within each province with a two city-level linear DID models. The DID model is

$$
\text { PM }_{2.5 i j}=\beta_{0}+\beta_{1} \text { Post }_{i j} \times \text { Cleanheating }_{i}+\beta_{2} X_{i j}+\text { Date }_{j}+\text { City }_{i}+\varepsilon_{i j}
$$

where $P M_{2.5 i j}$ is the dependent variable associated with city $i$ 's air pollution concentrations on date $j$. We select the reduction of concentration of $\mathrm{PM}_{2.5}$ to reflect the effects of clean heating and to calculate the health benefits furtherly. This is because on one side, particulate matters are main air pollutants released by the incomplete combustion of coal in heating boilers (Almond et al., 2009). On the other side, $\mathrm{PM}_{2.5}$ causes serious damage to human health (Ferris et al., 1979). We select the period from November $15^{\text {th }} 2013$ to March $15^{\text {th }} 2018$ as the research period ${ }^{2}$. Independent variables Post $_{i j}$ is a dummy variable which indicates whether date $j$ is post $15^{\text {th }}$ November 2016 which is the start of the clean heating policy. Cleanheating ${ }_{i}$ is another dummy variable and has a value of 1 if city $i$ is in the clean heating cities group and 0 if the city is in the control group. $\beta_{1}$ is the coefficient for the interaction term which measures the clean heating treatment effects. We collect the weather characteristics in $X_{i j}$ as controls, which include the average temperature, relative humidity, maximum speed of wind, a binary indicator for whether the day is public holiday. We further include the fixed effects in this model, where Date $_{j}$ reflects the daily fixed effects and City reflects the individual fixed effects to flexibly control for city heterogeneity. $\varepsilon_{i j}$ is the random error term.

The clean heating cities are the treatment group and the other 30 cities of Hebei, Shandong, Henan and Shanxi provinces which have not implemented clean heating are

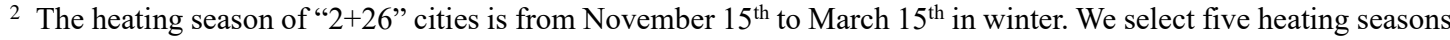
as the research period from November $15^{\text {th }} 2013$ to March $15^{\text {th }} 2018$.
} 
the control group in the DID model. Both treatment and the control groups belong to a temperate monsoon climate, have similar levels of economic development level and population density, and suffer serious air pollution in winter. We also test and verify the hypothesis of common trends between treatment group and control group for the DID model (see Fig. A1.).

The main data sets used in the DID model are the air pollution data of $\mathrm{PM}_{2.5}$ and the daily meteorological conditions for cities. The daily city-level concentrations of $\mathrm{PM}_{2.5}$ are derived from the National cities' daily air quality report published by the Ministry of Ecology and Environment of China (MEE). Meteorological conditions affect emissions and air quality ( $\mathrm{Fu}$ and $\mathrm{Gu}, 2017$; Viard and $\mathrm{Fu}, 2015)$. The concentrations of particulate matter are affected by precipitation and wind speed (Jones et al., 2010; Rost et al., 2009). The daily meteorological factors include wind speed, humidity, temperature, and precipitation which are downloaded from the website. ${ }^{3}$ Moreover, air pollution increases significantly during weekends and holidays because of increased travel and industrial emitters ( $\mathrm{Fu}$ and $\mathrm{Gu}, 2017$ ). We also control for the weekend and holiday effects.

\subsubsection{Health and economic effects estimation}

Based on the DID model, we get the change of $\mathrm{PM}_{2.5}$ concentration caused by the clean heating policy. Combined with the exposure-response function, the impacts of clean heating on health are estimated. The heavy metals and microorganisms on the surface of $\mathrm{PM}_{2.5}$ would damage the respiratory and cardiovascular systems by penetrating cells and affecting blood circulation (Schwartz, 1994; Schwartz et al., 2002). The diseases of respiratory and cardiovascular systems may cause mortality, hospitalization or sick leave. All of these health effects are estimated in this paper with the Poisson regression proportional risk model:

$$
R R=R R_{0} \times \exp \left(\beta \times\left(\mathrm{C}-C_{0}\right)\right)
$$

where $R R$ is the relative risk of the effects of $\mathrm{PM}_{2.5}$ on human health under clean heating scenario, $R R_{0}$ is the baseline relative risk of human health under baseline scenario without clean heating; $\mathrm{C}$ denotes the concentration of $\mathrm{PM}_{2.5}$ after the implementation of clean heating, $\mathrm{C}_{0}$ is the baseline concentration of $\mathrm{PM}_{2.5}, \beta$ is the

\footnotetext{
${ }^{3}$ Weather conditions at city level are from the website: $\langle$ http://www.tianqihoubao.com/lishi/ $\rangle$ (in Chinese). 
coefficient of exposure-response, which indicate the percentage decrease in morality or other health outcomes for each unit decline of $\mathrm{PM}_{2.5}$ concentration.

When the exposure population is $P$, the change of health effects of $\mathrm{PM}_{2.5}$ is calculated by Eq. (7):

$$
\Delta E=P \times\left(R R-R R_{0}\right)=P \times R R \times\left\{1-\frac{1}{\exp \left[\beta \times\left(C-C_{0}\right)\right]}\right\}
$$

The decline in $\mathrm{PM}_{2.5}$ concentration brings the health benefits on mortality, hospitalization or chronic illness, and avoids the additional health expenditure and economic loss of absenteeism caused by illness. We estimate the health economic benefits of the controlling of $\mathrm{PM}_{2.5}$ by Eq. (8):

$$
L=\sum_{i=1}^{\mathrm{m}} L_{i}=\sum_{i=1}^{\mathrm{m}} P \times\left(R R_{i}-R R_{0 i}\right) \times L_{p i}
$$

where $L$ represents all economic benefits, $L_{i}$ is the economic benefits from health $\operatorname{loss} i, L_{p i}$ is the per unit economic benefits from health loss $i$.

Then, according to the regression analysis of the relationship between the average expenditure of outpatient and inpatient cases and the per capita GDP, the regression parameters $\beta$ of medical costs at province-level are obtained. Regression analysis also showed the average costs of hospitalization for cardiovascular diseases, cerebrovascular diseases and respiratory diseases. The data for all-cause premature deaths, death rate, number of inpatients, the average expenditure of outpatient cases and inpatient cases come from the China Health and Family Planning Yearbook 2007-2015 (National Health and Family Planning Commission, 2008-2016). The urban population and GDP is from Beijing Statistical Yearbook 2017-2018 (Beijing Municipal Bureau of Statistics, 2017-2018), Tianjin Statistical Yearbook 2017-2018 (Tianjin Municipal Bureau of Statistics, 2017-2018), Hebei Economic Yearbook 2017-2018 (People's Government of Hebei Province, 2017-2018), Shandong Statistical Yearbook 2017-2018 (People's Government of Shandong Province, 2017-2018), Shanxi Statistical Yearbook 2017-2018 (People's Government of Shanxi Province, 2017-2018) and Henan Statistical Yearbook 2017-2018 (People's Government of Henan Province, 2017-2018). 


\section{Results}

\subsection{The number of clean heating transformation household}

Clean heating policy was implemented in November 2016. Through the end of 2018, the heating modes of more than 11 million households have been transformed into clean heating. The target of clean heating in 2020 was $73 \%$ complete. Half of the total was completed in 2017 and 2018, respectively. A total of 8272k households have switched to gas heating equipment, including 4589k in 2017 and $3683 \mathrm{k}$ in 2018 . As the project of replacing coal with natural gas was called off in November 2017, the transformation task in 2018 decreased by $20 \%$ compared with that in 2017 . The number of households whose heating equipment were transformed to electricity increased from $1216 \mathrm{k}$ in 2017 to $2101 \mathrm{k}$ in 2018 . On the whole, the transformation of clean heating is still dominated by gas heating, which accounts for $70 \%$ of the total households.

As shown in Fig. 2.A, Beijing, Tianjin, Langfang, Baoding and Shijiazhuang (the latter three cities belong to Hebei province) had more than 600 thousand households which underwent natural gas heating transformation. Due to the gas shortage in JingJin-Ji, the number of households switching to gas transformation in these cities dropped greatly in 2018. In cities of Henan and Shanxi provinces, such as Jincheng, Hebi and Anyang, the transformation speed of natural gas heating implemented was slow and the transformation size was small in 2017. To realize the clean heating target in 2020, these cities stepped up their renovation efforts in 2018. Fig. 2.B shows that the Beijing and Tianjin have the largest number of households with electric heating transformation, 680k and 397k, respectively. In 2018, more households have been involved in coal-toelectricity transformation in each city. 
A

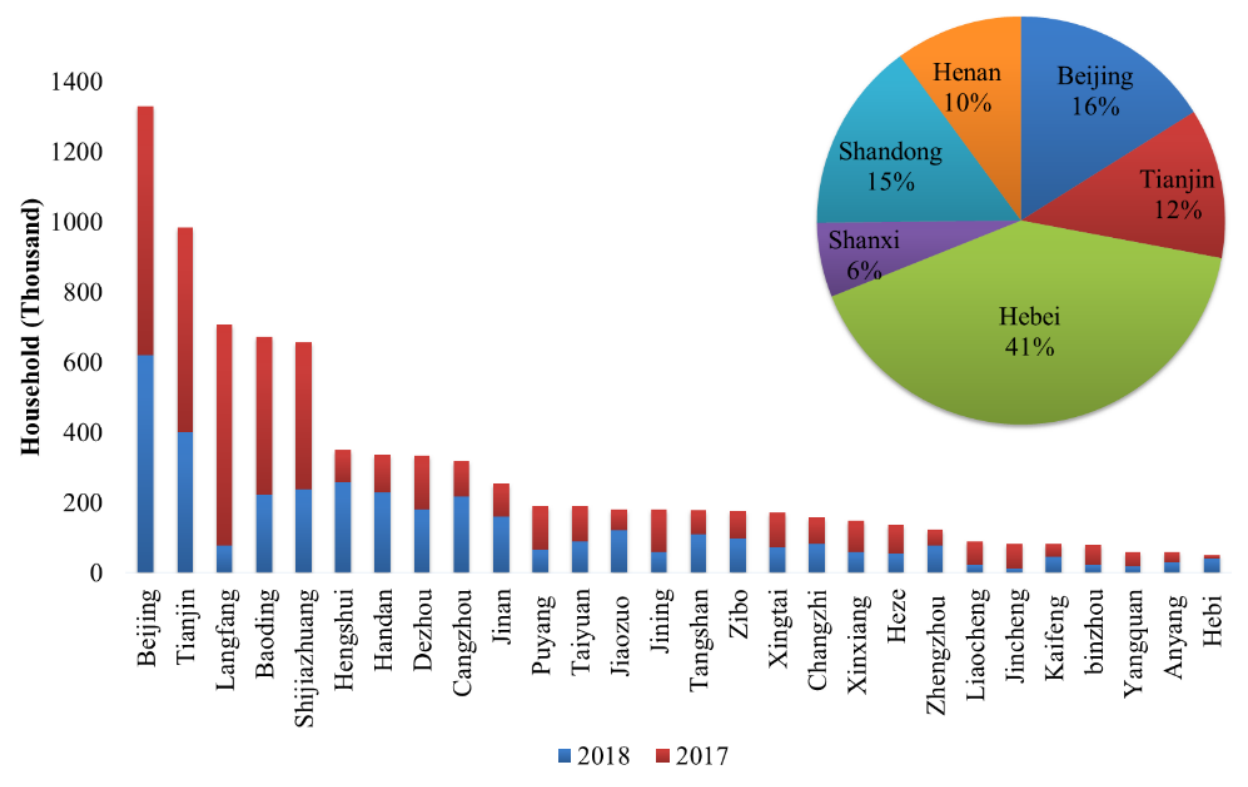

B

Coal to electricity

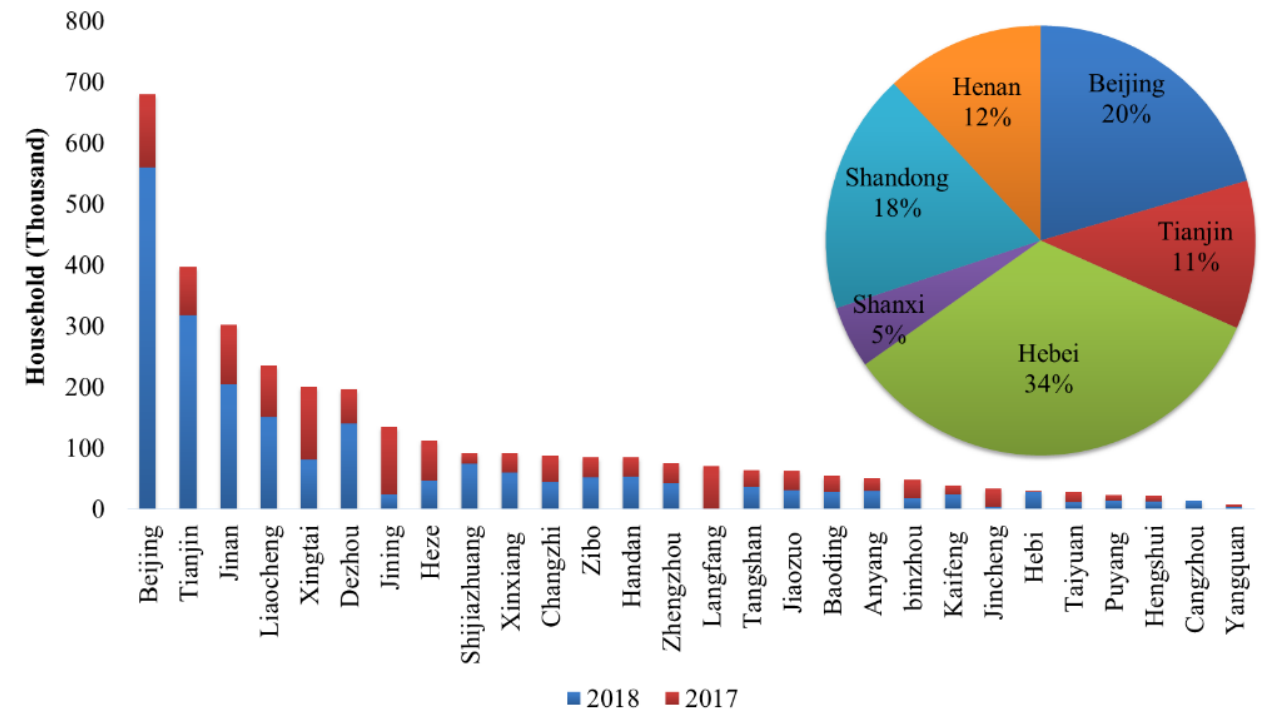

Fig. 2. Household number of clean heating transformation from 2017 to 2018

In addition to the introduction of the natural gas and electric heating, new energy heating was also implemented in Hebei province. Cities such as Tianjin and Zhengzhou only put forward to encourage renewable energy heating in the provincial Clean Heating Plan, and there was no specific task for the number of transformationhouseholds. Hebei has clearly put forward the task of transformation household for each city. Winter Clean Heating Work Plan 2018-2020 of Hebei Province proposed to complete the new heating transformation of 32000 households, which included pilot 
graphene and integrated energy heating in Handan, Shijiazhuang, Zhangjiakou and other cities, pilot biomass heating in Handan, pilot alcohol-based fuel in Xingtai, pilot geothermal heating in Baoding, and pilot photovoltaic and solar thermal heating throughout the whole province. This new heating transformation programme is still in the pilot stage. Only six cities adopted new energy heating transformation in 2018 and the ratio of household with new energy heating in total clean heating ranges from $0.02 \%-1.5 \%$. The ratio at province level was less than $0.08 \%$, which has very little impact on our results. Hence, we only considered the cost of clean heating mode of replacing coal with gas and electricity.

\subsection{Costs}

\subsubsection{Costs of government}

Multi-level governments including the central government, provincial-level government and the city-level government provide for the clean heating costs, which contain the subsidy for natural gas or electric heating transformation, the cost of central heating transformation, cost of building energy saving transformation and other costs. The subsidy for natural gas or electricity transformation accounts for the largest share of the total costs.

The central government has provided financial subsidy for clean heating transformation of " $2+26$ " cities since November 2017. The subsidies range from 1 billion yuan per year for provincial-level cities to 0.5 billion yuan per year for prefecture-level cities. In addition to the subsidy from central government, the provincial government also provides subsidies for the cities' clean heating transformation. All subsidies are mainly spend on the initial costs and operation costs for transformation of natural gas, electricity or renewable energy heating. The initial costs include the equipment subsidy and the pipeline construction cost, which are the one-time subsidy. The operation costs include the electricity allowance and gas allowance for household and is provided for each heating season with last for three years. We calculate the government's subsidy cost for natural gas heating and electric heating, respectively.

Table A1 reports the subsidy standards for gas heating transformation of " $2+26$ " cities, which include the equipment subsidy and pipeline subsidy for one-time, and the operation subsidy for three heating seasons. The proportions of equipment subsidies are 
generally more than 50\%. The maximum equipment subsidies for each household range from 2000 yuan in Jinan, Yangquan, Binzhou and Kaifeng to 7200 yuan in Beijing. For operation subsidy, due to the difference of unit gas price subsidy and subsidized gas volume among cities, the maximum operation subsidies for each household in each heating season range from 600 to 2400 yuan. The lowest operation subsidy is funded by six cities in Henan province and the highest one is from Beijing. There are 12 cities supplying subsidy for pipeline reconstruction. The cities are mainly located in Hebei and Shanxi provinces, except for Beijing. On the whole, the standards of subsidies vary greatly from city to city. The amounts of subsidies in Beijing and Tianjin are higher, and the proportion of subsidies are larger, while the subsidy of Henan is relatively lower.

Based on the data of the number of transformation households and the different subsidy, we calculate the total subsidy of natural gas heating of each city. The results are shown in Fig. 3. Due to the postponement of additional transformations, the total subsidy decreased by 16\% in 2018 (5.8 billion yuan) than that in 2017 (6547 billion yuan). The total subsidy of Hebei province is the largest, which is contributed from the larger number of households in Shijiazhuang, Hengshui, Baoding and Handan. The government of Henan province provided the lower subsidy than other regions, because of the lower equipment and operation subsidy and the lack of a pipeline subsidy for each household, for example in prefecture-level cities like Jiaozuo and Anyang. At the city level, Beijing's subsidies in 2017 and 2018 are the highest, reaching 0.67 billion yuan in 2018. 


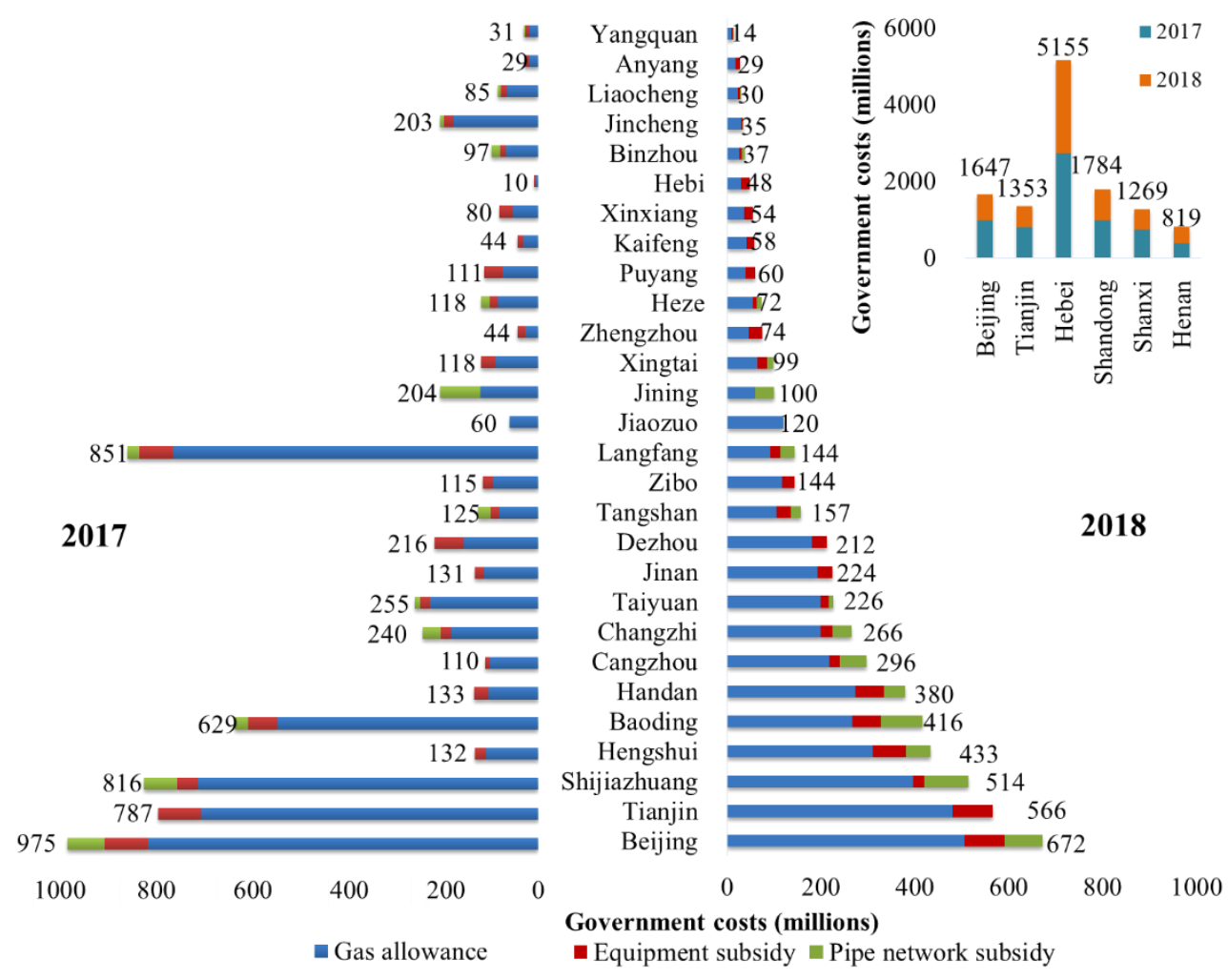

Fig. 3. Subsidy for gas heating from 2017 to 2018

The subsidy standards for electric heating transformation include the equipment subsidy for one-time and the operation subsidy for three heating seasons (as shown in Table A2). The maximum subsidies for electric heating equipment range from 2000 yuan in Jinan and Kaifeng to 12000 yuan in Beijing. In terms of operation subsidy, the maximum subsidies for each household in each heating season range from 420 to 2400 yuan. The higher subsidies are from Taiyuan, Beijing and cities in Hebei province, the lower subsidies are from cities in Henan province. For the total government subsidy cost, the subsidy in 2018 increased by $48 \%$ over that in 2017 , reaching up to 3 billion yuan. As shown in Fig. 4, the governments of Hebei and Shandong provinces invested in larger subsidies for electric heating transformation. At the city level, the subsidies by Beijing, Tianjin and Jinan exceeded than 2 billion yuan in 2018. 


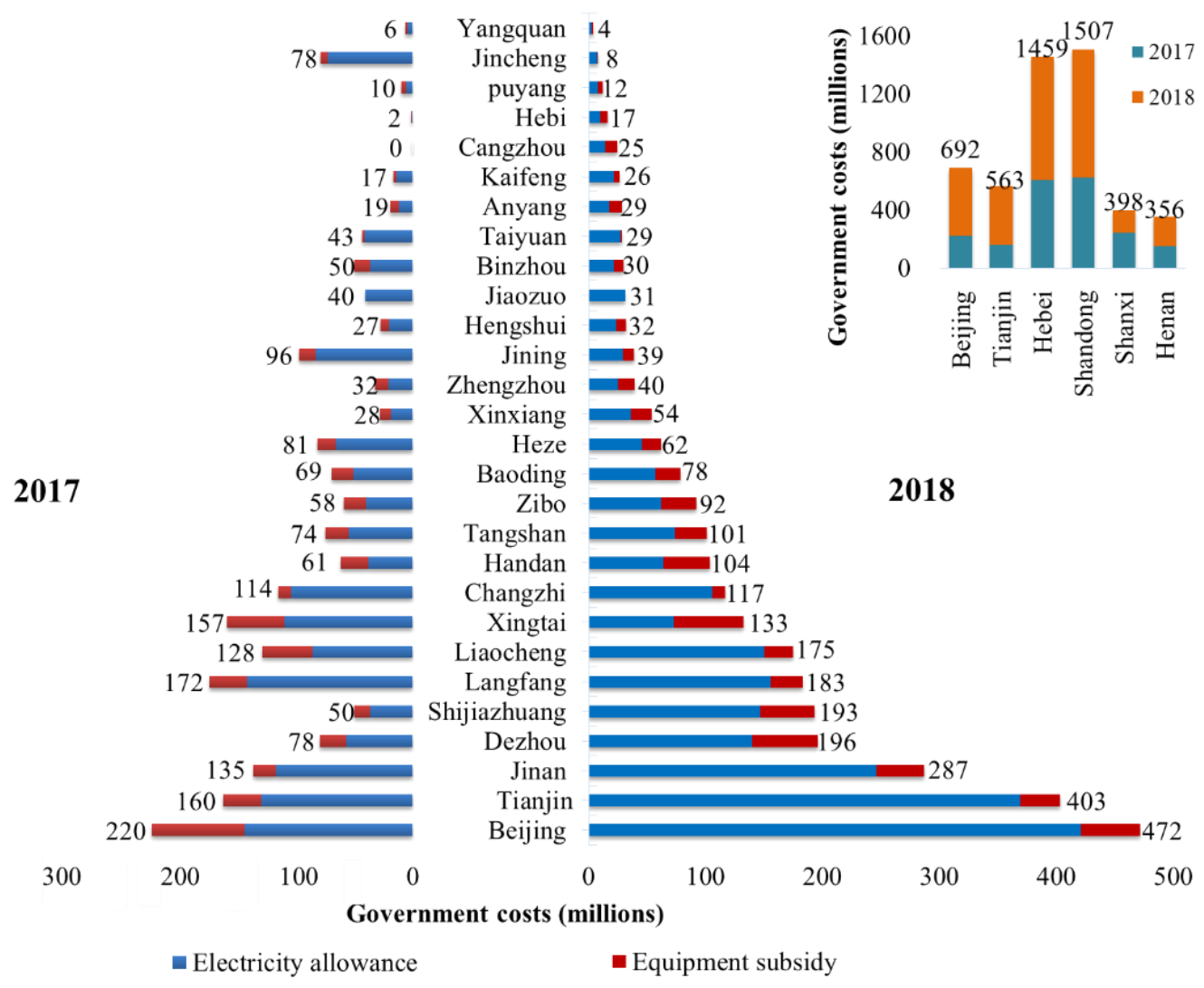

Fig. 4. Government subsidy cost of electric heating transformation from 2017 to 2018

Based on the above statistics, we calculate the total costs to the government and find the cost of 2018 ( 15.4 billion) is $80 \%$ higher than that of 2017 ( 8.5 billion); this is because of the second operational subsidy for transformation households in 2017. The subsidies for natural gas and electric heating transformation account for more than $99 \%$ of the total government cost of " $2+26$ " cities. Other costs account for the left $1 \%$, which contain the subsidy for renewable energy heating, cost of central heating transformation, cost of building energy saving transformation and cost of heating transformation of activity room for residents. Fig. 5. presents that the government costs of Beijing, Shijiazhuang and Tianjin were more than 2 billion. The costs of cities in Hebei province are much higher, such as Baoding and Langfang. The total input of Hebei government is the largest at the province-level. Due to the lower subsidy to households, the total government cost of Henan is the lowest. 


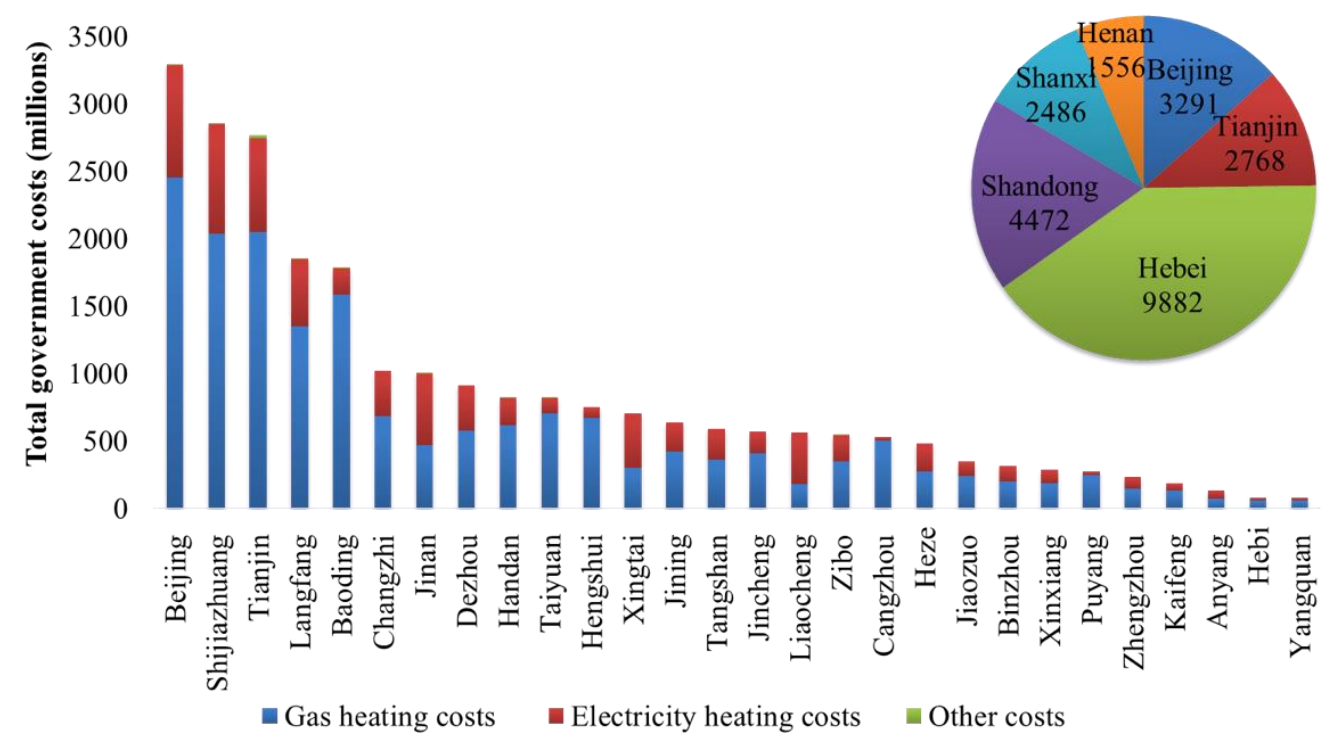

Fig. 5. The total costs of governments

\subsubsection{Costs to residents}

In the process of clean heating implementation, residents need to replace the coalfired heating equipment with the clean heating one or buy the new equipment. Although the governments provided subsidies for equipment purchase, the residents still needed to spend $15-50 \%$ of the cost of the natural gas or electric heating equipment. Besides, the heating fuel fee of the clean heating is much higher than that of the traditional coalfired heating. For example, the cost of coal-fired heating for one heating season of each household is about 1600 yuan, while the costs of gas heating and electric heating are about 4000 yuan and 3600 yuan (Luo and Li, 2018). The extra heating fee under the new heating mode should be paid by the residents.

The total cost of each household for clean heating is the sum of equipment cost and operation cost minus the subsidy from the government. Fig. 6 shows that the total cost to residents of Beijing, Tianjin, Jinan, Dezhou and Shijiazhuang was more than 1 billion. The residential costs to cities in Shanxi province was much lower, such as Jincheng, Yangquan and Taiyuan. One reason is fewer transformation households. The other reason is that government subsidies account for a higher proportion of heating costs, and the heating fees paid by residents were relatively low. 


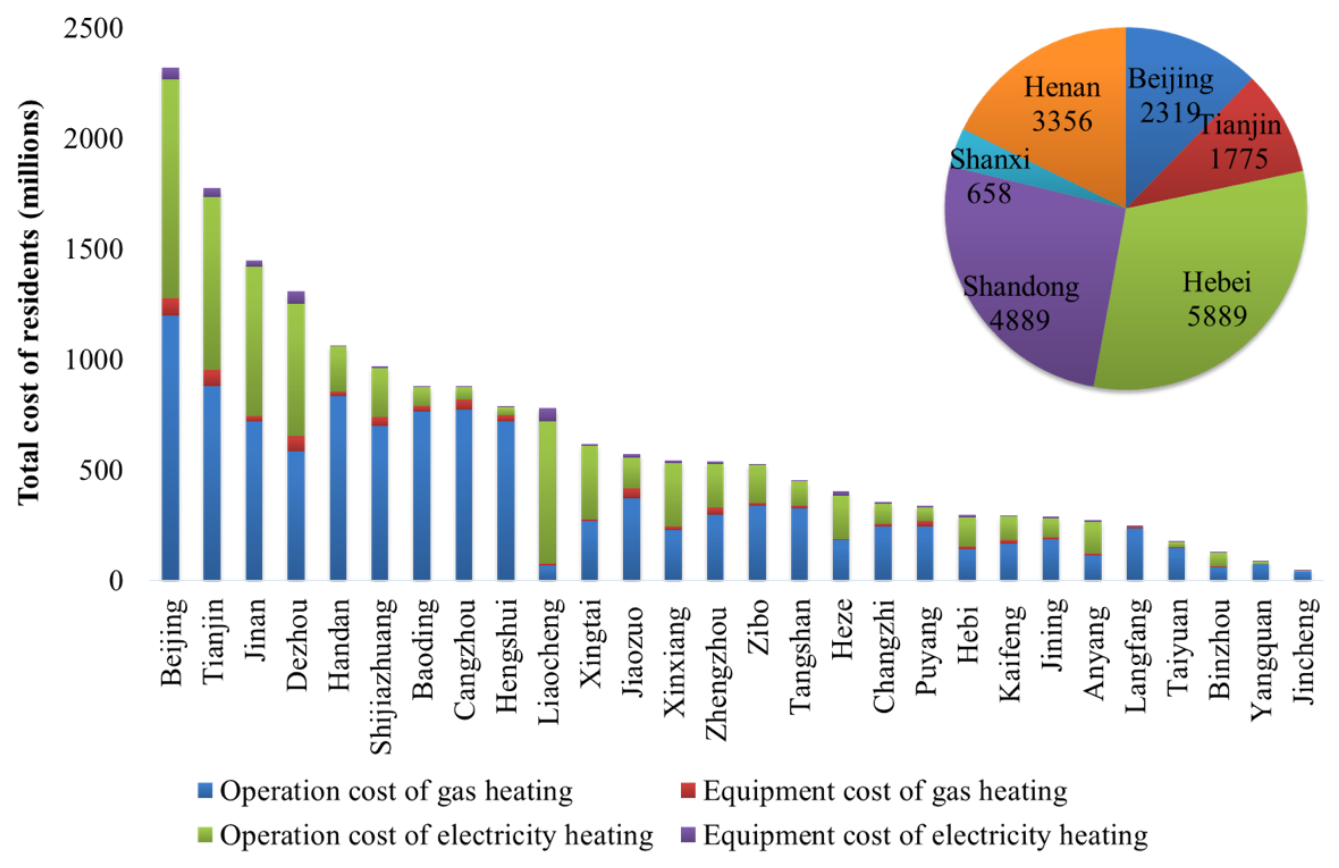

Fig. 6. The total cost of resident

Due to the different subsidies of each government, clean heating brings different degrees of economic burden to the residents of each city. Here, we examine the impact of different heating modes on the economic burden of residents in different regions. As shown in Fig. 7, none of the cities is in the heating poverty situation under the coalfired heating, the average of ratio of heating cost (RHC) is 6.28. While after the transformation of clean heating, there are $82 \%$ and $64 \%$ of all cities under the heating poverty with gas heating and electric heating, respectively. The averages of RHC under two clean heating mode are 12.7 and 11.9, which are in heating poverty. With the implementation of clean heating, there is no city under the not burdened situation. In general, clean heating burdened residents by higher heating cost which led to heating poverty.
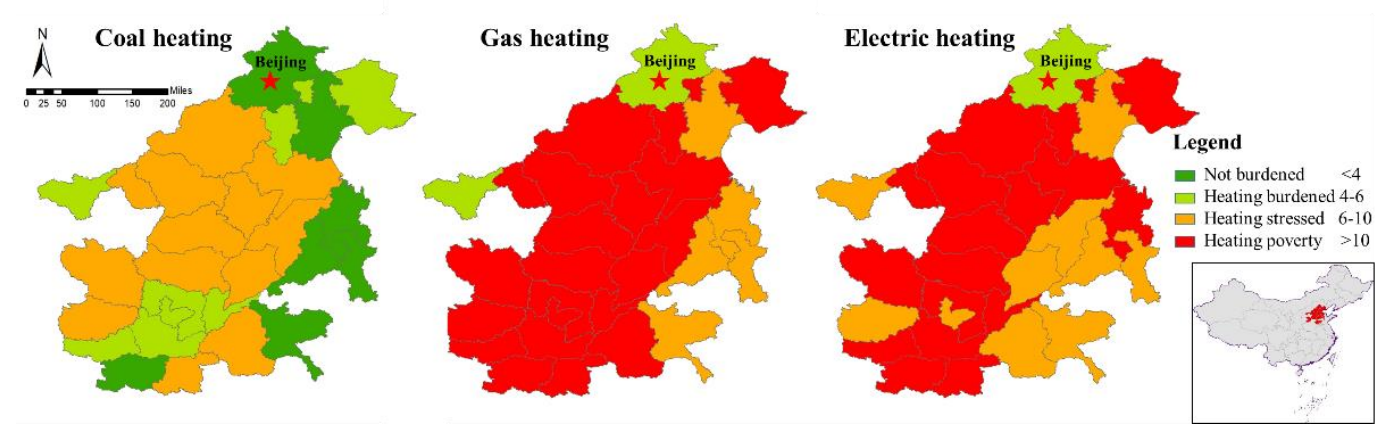

Fig. 7. Heating burdened of households in " $2+26$ " cities under different heating mode 
We also find the impacts of clean heating on heating burdens differ at the city level. For example, the RHC of Taiyuan, the capital city of Shanxi province, changed from 5.88 under coal heating to 5.99 under gas heating and 7.67 under electric heating. The clean heating does not change the heating bill greatly and does not put a heavy burden on the residents, because the government has been responsible for large part of the heating cost for the residents by providing subsidy (see Table A1 and Table A2). While the impacts on Yangquan, a prefecture-level city in Shanxi province, are different. Due to the lower subsidy, residents in Yangquan need to bear more of the heating cost and experience heating poverty (RHC 16.35 for gas heating, 15.45 for electric heating) from heating stressed (RHC 6.81). The current subsidies for provincial capital city and prefecture-level city mechanism are 700 million yuan and 500 million yuan per year. Moreover, the income of residents in provincial capital cities is much higher than that of residents in prefecture-level cities. The unequal subsidy increases the heating burden on low-carbon households.

\subsubsection{Total costs}

Based on the costs to governments and residents, we calculate the total costs of clean heating from 2017 to 2018, which is up to 43.1 billion yuan. The costs to government accounts for $44 \%$ and that to residents accounts for $56 \%$. At the provincial level, the total costs to Hebei province is the largest with 16.1 billion yuan. Shandong is the second province (see Fig. 8). Due to having the fewest transformation households, the total costs to Shanxi is the lowest. At the city level, the total costs to Beijing, Tianjin and Shijiazhuang are more than 3 billion and the costs to government account for the larger share. Residents are stressed by the larger share of heating bills in other cities, such as Jinan, Dezhou and Jiaozuo. 


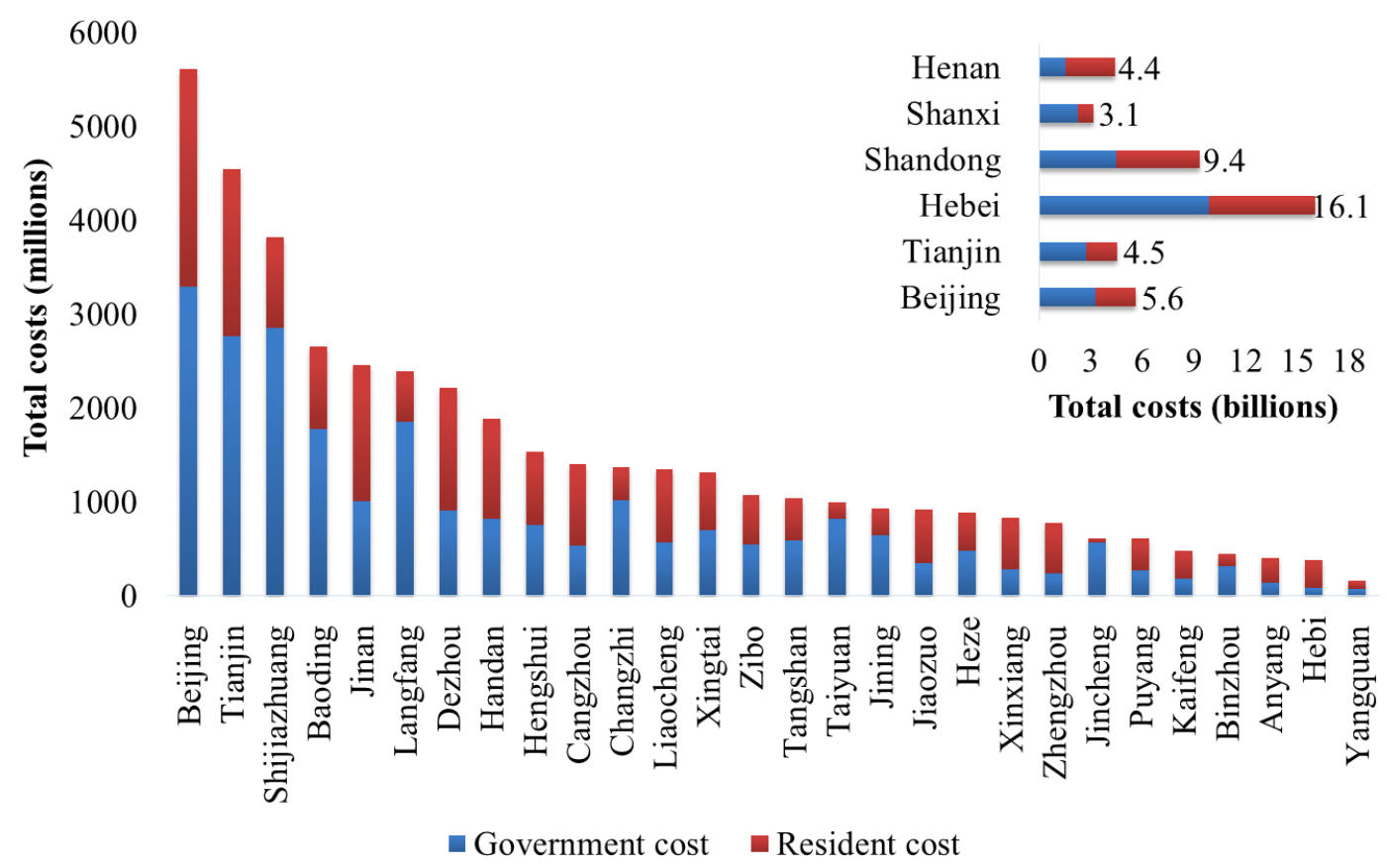

Fig. 8. Total costs of clean heating from 2017 to 2018

\subsection{Benefits}

\subsubsection{Environmental benefits}

We estimate the effects of clean heating on daily air pollution and treat the clean heating policy as an exogenous "policy" and apply the difference-in-differences model, using flexible time trends and city-level fixed effects to control the unobserved confounding factors and also controlling for the meteorological factors that affect urban air pollution.

Table 1 shows the effects of clean heating on the concentrations of $\mathrm{PM}_{2.5}$ for each province with the comparison of control cities and treatment cities in the same province. The coefficients of the interaction term between the Post dummy and the Cleanheating dummy of all models are negative significantly, which indicate that the clean heating has dropped the concentrations of $\mathrm{PM}_{2.5}$ of clean heating cities relative to cities without implementation of clean heating. The concentrations of $\mathrm{PM}_{2.5}$ decreased by 11.597 $\mu \mathrm{g} / \mathrm{m}^{3}$ of Hebei, $7.692 \mu \mathrm{g} / \mathrm{m}^{3}$ of Henan, $7.937 \mu \mathrm{g} / \mathrm{m}^{3}$ of Shandong and $7.320 \mu \mathrm{g} / \mathrm{m}^{3}$ of Shanxi. We also find clean heating decreased the daily air quality index and concentrations of $\mathrm{PM}_{10}$, sulfur dioxide and nitrogen significantly (see Table A3). The environmental improvements brought by clean heating suggest that the promoting clean fuel in the residential heating sector helps to improve the air quality and to bring about a decline in the air pollutants in winter in BTH and surrounding areas. At the province- 
level, the decline of $\mathrm{PM}_{2.5}$ is the largest in Hebei, followed by Shandong, Henan and Shanxi. There are correlations between the decline in $\mathrm{PM}_{2.5}$ and the number of households with clean heating transformation. The larger number of clean heating households contribute to a greater decline in air pollutants in winter. Moreover, as the center area of the pollution transmission channel of BTH, Beijing has received the benefits of externality from the improvement of air quality in other areas.

Table $1 \mathrm{DiD}$ estimation on the effects of clean heating

\begin{tabular}{lcccccc}
\hline & Beijing & Tianjin & Hebei & Henan & Shandong & Shanxi \\
& $(1)$ & $(2)$ & $(3)$ & $(4)$ & $(5)$ & $(6)$ \\
\hline Post $\times$ Clean heating & $-8.631^{* * *}$ & $-7.701^{* * *}$ & $-8.497^{* * *}$ & $-7.692^{* * *}$ & $-7.937^{* * *}$ & $-7.320^{* * *}$ \\
& $(2.987)$ & $(2.387)$ & $(2.864)$ & $(2.371)$ & $(2.454)$ & $(2.137)$ \\
Observations & 18755 & 18755 & 6655 & 10285 & 10285 & 6655 \\
$\mathrm{R}^{2}$ & 0.304 & 0.298 & 0.491 & 0.378 & 0.391 & 0.397 \\
\hline
\end{tabular}

Note: All models included the city-level daily average temperature, daily relative humidity, daily precipitation, daily maximum wind speed, weekend dummy and holiday dummy. In model (1) and model (2), we select Beijing and Tianjin as the treatment city, respectively, and select the other 30 non-clean heating cities belonged to Hebei, Shandong, Shanxi and Henan as the control group. To meet the comparability between the municipality level city and prefecture-level city, we employ the propensity score matching (PSM) with the meteorological variables as the propensity variables before using DID estimation. In model (3)-(6), the clean heating cities of each province were in the treatment group, other cities in the same province without implementation of clean heating were the control cities. The samples of model (3) - (6) include 11 cities in Hebei Province, 17 cities in Henan Province, 17 cities in Shandong Province and 11 cities in Shanxi Province, respectively. Robust standard errors are in the parentheses. Standard errors are clustered at the city level. ${ }^{* * *} p<0.01 ;{ }^{* *} p<0.05 ;{ }^{*} p<0.1$

\subsubsection{Health and economic benefits}

Based on the variation of $\mathrm{PM}_{2.5}$ concentrations, we estimate the effects of clean heating on health benefits at province level with the exposure-response model. As Fig. 9 shows, in total, there are 242.39 thousand persons (95\% CI: 49.43-352.86) benefiting from clean heating policy. The number of inpatients with respiratory disease and cardiovascular disease decreased by 29.27 thousand persons (95\% CI: 0-59.60) and 29.41 thousand persons ( $95 \%$ CI: 18.38-40.27), respectively. The number of outpatients with internal medicine or pediatrics dropped by 122.94 thousand persons (95\% CI: 16.04-151.45) and 8.00 thousand persons (95\% CI: 1.37-10.94). There are 52.77 thousand persons (95\% CI: 13.43-90.60) who avoided premature deaths. 


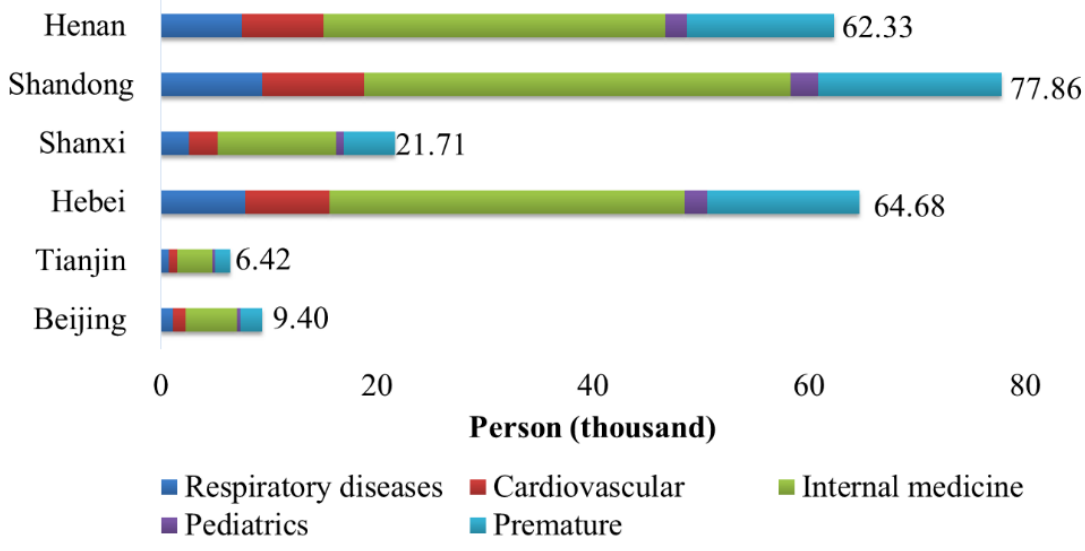

Fig. 9. Number of people benefiting from clean heating

At the province-level, Shandong has the highest number of inpatients (including respiratory and cardiovascular diseases), outpatients (including internal medicine and pediatrics), and the largest number of premature deaths. Shandong has the largest population of people exposed to air pollution, hence, the improvement of the air quality can bring greater health welfare to their society. In contrast, for Shanxi, with both the smallest population among the four provinces and the least decline in $\mathrm{PM}_{2.5}$ concentrations contribute the lowest number of persons with health benefits.

As shown in Fig.10, the health economic benefits are 109.85 billion yuan (95\% CI: 22.40-159.83), 95\% of which could be attributed to the decline in cardiovascular and respiratory diseases inpatients. The health benefits from cardiovascular and respiratory diseases inpatients, internal medicine and pediatrics and premature deaths saved 293.35 billion, 751.38 billion, 16.36 billion, 4.29 billion and 33.16 billion yuan, respectively. At the province level, the health economic benefits of Shandong are the highest with 35.68 billion yuan. In contrast, that of Shanxi are the lowest, with 9.21 billion yuan. The GDP per capita, average hospitalization cost, average medical expenses are different among regions. These related parameters are the highest in Beijing. 


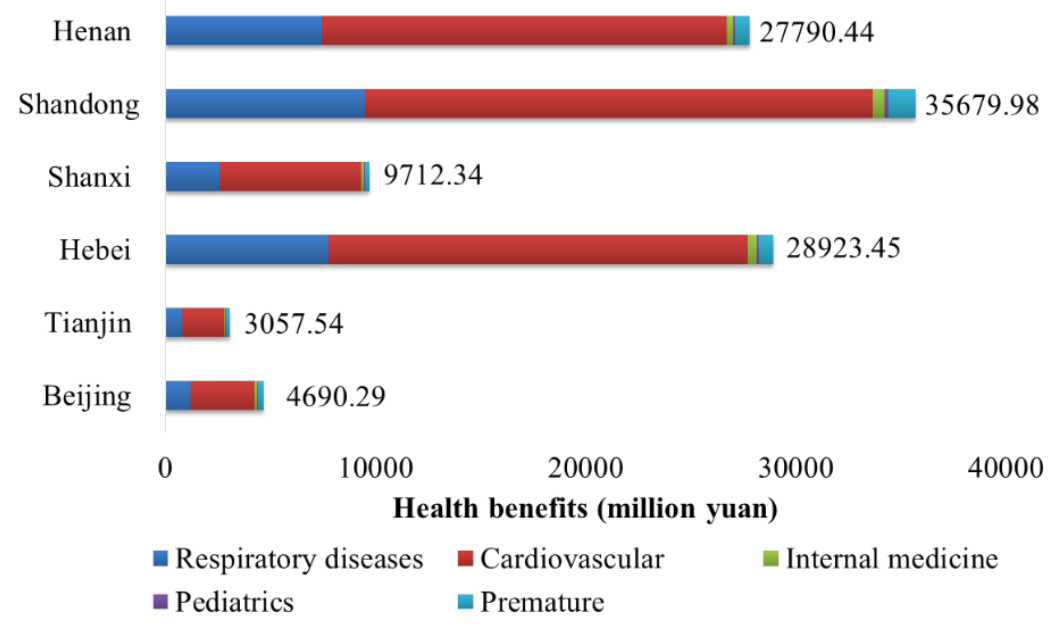

Fig. 10. Health economic benefits from clean heating policy

\subsection{Net Benefits}

We estimate the economic effectiveness of clean heating policy. Results are shown in Fig. 11. For all regions, the total health economic benefits are larger than the total costs with net benefits of 35.2 million. The net benefits to Beijing, Tianjin, Hebei, Shanxi, Shandong, and Henan are 1399.29, 289.54, 19041.45, 7226.34, 31207.98 and 26234.44 million, respectively. The largest net benefits are to Shandong, which contributes the largest health benefits.

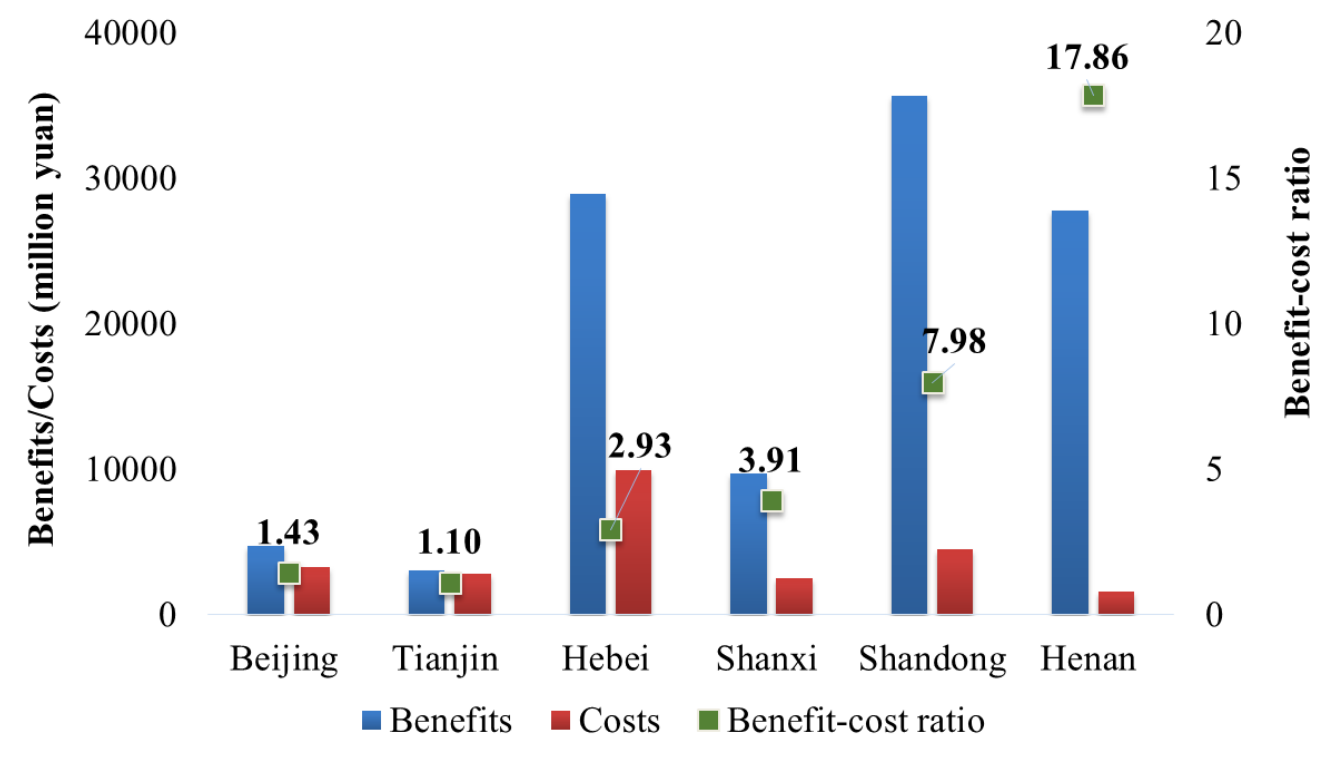

Fig. 11. Total benefits and costs of clean heating policy.

Note: column charts represent the cost (red columns) and the benefits (blue columns), respectively. Scatter charts represent the benefit-cost ratio for six regions. 
The average cost-benefit ratio of clean heating policy is 1:4.49. At region level, the highest cost-benefit ratio is to Henan (1:17.86). Although the costs to Henan is the lowest, the health benefits are not the lowest one due to the medium ranking of $\mathrm{PM}_{2.5}$ improvements and per capita GDP. Shandong, Shanxi and Hebei rank the second, third and fourth with the cost-benefit ratio of 1:7.98, 1:3.91 and 1:2.93. For the municipalities, the benefits are higher than the costs, while the difference is not great. The cost-benefit ratio of Beijing and Tianjin are 1:1.43 and 1:1.10, respectively. These ratios are lower than that of the above four provinces. Although the PM2.5 concentrations reduction of provinces and municipalities are similar, more people in the provinces are exposed to the improved air quality compared with municipalities. For example, the population of Beijing and Tianjin are 21.5 million and 15.6 million, respectively. While that of Hebei, Henan, Shandong and Shanxi provinces range from 37.3 million to 100.7 million, which are almost 2-10 times as that of the municipalities (National Bureau of Statistics, 2020). In general, the health welfare exceeds the total costs to residents and governments. Thus, the clean heating policy has considerable net benefits. In the long run, if clean heating is carried out continuously, air quality will continue to improve and the society will obtain greater net benefits.

\section{Conclusion and policy implications}

Clean heating was launched in " $2+26$ " cities in China in 2016 with the aim to promote the use of clean fuel in the residential heating sector and to improve air quality. Our study makes a comprehensive evaluation of the impacts of this clean heating policy on both governments and residents and quantifies the environmental and health benefits of clean heating.

Our results were subject to a series of uncertainties and limitations. First, we only consider costs including the government subsidy costs for equipment and allowance and residents heating fees. The loss of the remaining expected value of old heating equipment is not taken into account due to lack of detailed information about the eliminated equipment, which might, in turn, have underestimated the total costs of the clean heating. Second, as an econometric model, the difference-in-differences model could not control for all variables that might affect air pollution in the model. We conduct a large set of robustness checks, such as using different samples, adding different control variables, and a time placebo test. Robustness checks confirm the 
validity of our findings (see Table A3). Our estimation indicates clean heating decreased the concentrations of $\mathrm{PM}_{2.5}$ which is supported by previous studies. For example, He et al. (2019) reported compared with the concentrations of $\mathrm{PM}_{2.5}$ in winter of 2016, the concentrations of $\mathrm{PM}_{2.5}$ dropped by $27.17 \mu \mathrm{g} / \mathrm{m}^{3}\left(109.5 \mu \mathrm{g} / \mathrm{m}^{3}\right.$ to $\left.82.33 \mu \mathrm{g} / \mathrm{m}^{3}\right)$ on average of " $2+26$ " cities in 2018 .

The huge financial investments have brought enormous environmental and health benefits. In terms of costs, the total costs of clean heating were up to 43.1 billion yuan, which mainly came from replacing coal with natural gas or with electricity. Governments and residents account for $44 \%$ and $56 \%$ of the total costs, respectively. In terms of benefits, clean heating project is effective for air pollution control and brings health-economic benefits about 109.85 billion yuan (95\% CI: 22.40-159.83). This result shows that the clean heating policy should be identified as a net benefit program with environmental and health improvements. It is well worth promoting this policy in the central heating areas of Northern China in order to control the air pollutants emitted by heating boilers.

As the first step of environmental governance in the heating area, the clean heating policy in China is still in the exploration stage, and has some shortcomings. For example, clean heating increases the burden of heating fuel costs on residents to varying extent. On one side, some residents could not afford the higher heating fees and thus turn down the supply of heating, which result in the substandard indoor temperature. Especially in rural areas in Northern China, where most of the villagers are the elderly and children, residents could not afford the extra heating costs. The insufficient heating supply could assure the standard indoor temperature and thus decreases the comfort of heating with possible attendant health problems. On the other side, due to lower subsidies from government, the change of heating modes leads to heating poverty in residents. Currently, the clean heating subsidy from central government is classified by the administrative level of cities. Compared with prefecture-level cities, the municipalities and capital cities have been provided with much more financial support. In fact, the municipalities and capital cities have financial districts and residents have relatively high incomes. In the prefecture-level cities, economic development is relatively backward, and the local governments could not provide extra subsidies to the residents. Hence, clean heating put heavier burdens on the low-income residents in the less developed regions, especially in the rural areas. To some extent, it can be said that 
clean heating has further increased the gap between the rich and the poor.

We have made some progress in quantifying the degree of air pollution control achieved through this transformation in clean heating, but we have a long way to go before finding a scientific and reasonable clean heating policy with an optimal subsidy mechanism in China. One direction for improvement would be the One city, one policy for subsidy schemes. If a city is taken as a unit, central governments should make the subsidy standard based on its economic development, residential income level, energy resources, population, and air pollution characteristics. The less developed cities with large populations should be provided with higher financial subsidies. The local government should provide differential subsidies to urban and rural residents, and offer extra subsidies for poor households, so as to ensure the basic heating demand of residents is met and to avoid increasing the heating cost burden on residents. The new subsidy policy should minimize the negative impacts of clean heating policy on residents' energy poverty and energy consumption inequality.

In the long run, an efficient and flexible market mechanism should be introduced into the subsidy mechanism. We can explore the adoption of innovative modes such as company cooperation, village collective equity participation, Internet 'crowdfunding' and other ways to raise funds for the construction and operation of heating infrastructure, so as to reduce the financing costs, reduce the financial pressures on government, and meet the heating demand of residents. Another direction for improvements would be publicizing the energy and health benefits of clean heating to the public. Due to higher heating costs, some residents resist the clean heating transformation or burn the old raw coal-fired boilers for heating in secret. Local governments, especially the community workers, should expand the public messaging around the environmental and health benefits of new heating mode compared with coal-fired heating, so as to dissolve the public's resistance and reduce the possibility of coal-fired combustion. At the same time, public education and guidance can be fully achieved through messaging on TV, radio, wechat app and other platforms to demonstrate the use of equipment, improving villagers' user experience, enhancing villagers' recognition of the policy, and reducing the resistance to policy implementation. These recommendations can be made not only for China, but also for other emerging and middle-income countries who wish to adopt a clean heating agenda. 


\section{Acknowledgements}

This study was supported by the National Key R\&D Program of China (Grant no. 2018YFC0213600) and National Natural Science Foundation of China (Grant no. $71834004 ; 71673198 ; 71601140)$. We would like to thank the anonymous referees and the editors.

\section{Reference}

Agbim, C., Araya, F., Faust, K. Harmon, D., Subjective versus objective energy burden: A look at drivers of different metrics and regional variation of energy poor populations. Energy Policy, 144, 111616.

Almond, D., Chen, Y., Greenstone, M., Li, H., 2009. Winter Heating or Clean Air? Unintended Impacts of China's Huai River Policy. Am. Econ. Rev. 99, 184-190.

Beijing Municipal Bureau of Statistics, 2016-2018. Beijing Statistical Yearbook (2016-2018). China Statistics Press, Beijing.

Charlier, D., Risch, A., Salmon, C., 2018. Energy burden alleviation and greenhouse gas emissions reduction: Can we reach two objectives with one policy? Ecol. Econ. 143, 294-313.

Douglas, G., 2018 Lifting the Energy Burden on Low-Income Households. NREL Transforming Energy. https://www.nrel.gov/state-local-tribal/blog/posts/community-solar-lifting-the-energyburden-on-low-income-households.html.

Ferris, J.B.G., Speizer, F.E., Spengler, J.D., 1979. Effects of sulfur oxides and repairable particles on human health. Methodology and demography of populations in study. Am. Rev. Respir. Dis 120, 767-779.

Fu, S., Gu, Y., 2017. Highway toll and air pollution: Evidence from Chinese cities. J. Environ. Econ. Manag. 83, 32-49.

Gehrsitz, M., 2017. The effect of low emission zones on air pollution and infant health. J. Environ. Econ. Manag. 83, 121-144.

Guruswamy, L., 2011. Energy Poverty. Annual Rev. Enviro. Resour. 36(1):139-161.

He, K.B., Li, X., 2019. Report on the comprehensive control of bulk coal in China, Beijing (in Chinese).

Heltberg, R., 2004. Fuel switching: evidence from eight developing countries. Energy Econ. 26, 869-887.

Hosier, R.H., Dowd, J., 1987. Household fuel choice in Zimbabwe: an empirical test of the energy ladder hypothesis. Resour. Energy 9, 347-361.

Jones, A.M., Harrison, R.M., Baker, J., 2010. The wind speed dependence of the concentrations of airborne particulate matter and NO. Atmos. Environ. 44, 1682-1690.

Leach, G., 1992. The energy transition. Energy Pol. 20, 116-123.

Li, J., Cao, J., 2017. Empirical analysis of the effect of central heating on air pollution in China. China J. Econ. 4, 138-150.

Li, P., Lu, Y., 2020. The effects of fuel standards on air pollution: Evidence from China. J. Dev. Econ. 146, 102488.

Luo, Z., Li, H.R., 2018. The impact of Atmosphere Ten ariticles policy on air quality in China. China Ind. Econ. 9, 136-154. 
Mensah, J.T., Adu, G., 2015. An empirical analysis of household energy choice in Ghana. Renew. Sustain. Energy Rev. 51, 1402-1411.

Ministry of Ecological and Environmental of China, 2013. Air Pollution Prevention and Control Action Plan State Council Document Number 37 (in Chinese).

Ministry of Finance of China, 2017. Notice on carrying out the pilot work of financial support for clean heating in northern China (in Chinese).

Ministry of Ecological and Environmental of China, 2016. Air Pollution Prevention and Control Action Plan in Beijing-Tianjin-Hebei and surrounding areas (in Chinese).

National Bureau of Statistics of China, 2020. China Statistics Yearbook 2020. China Statistics Press, Beijing.

National Health and Family Planning Commission, 2008-2016. China Health and Family Planning Yearbook (2007-2015). National Bureau of Statistics. Union Medical College Press, Beijing.

Pang, J., Wu, J., Ma, Z., Liang, L.N., Zhang, T., 2015. Air pollution abatement effects of replacing coal with natural gas for central heating in cities of China. China Environ. Sci. 35, 55-61.

People's Government of Hebei Province, 2016-2018. Hebei Economic Yearbook(2016-2018). China Statistics Press, Beijing.

Pu, L., Wang, X.H., Tan, Z.F., Wu, J., Long, C.F., Kong, W.Z., 2019. Feasible electricity price calculation and environmental benefits analysis of the regional nighttime wind power utilization in electric heating in Beijing. J. Clean. Prod. 212, 1434-1445.

Qiu J, Y.L., 2000. Variation characteristics of atmospheric aerosol optical depths and visibility in North China during 1980-1994. Atmos. Environ. 34, 115-120.

Rost, J., Holst, T., Sahn, E., Klingner, M., Anke, K., Ahrens, D., Mayer, H., 2009. Variability of $\mathrm{PM}_{10}$ concentrations dependent on meteorological conditions. Int. J. Environ. Pollut. 36, 3-18.

Schwartz, J., 1994. Air pollution and daily mortality: a review and meta analysis. Environ. Resour. Econ. 64, 36-52.

Schwartz, J., Laden, F., Zanobetti, A., 2002. The concentration-response relation between PM2.5 and daily deaths. Environ. Health Perspect. 110, 1025-1029.

Sheehan, P., Cheng, E., English, A., Sun, F., 2014. China's response to the air pollution shock. Nat. Clim. Change 4, 306-309.

Tianjin Municipal Bureau of Statistics, 2016-2018. Tianjin Statistical Yearbook (2016-2018). China Statistics Press, Beijing.

Van, D.K.B., Brouwer, R., Van, P.J.H., 2013. The energy ladder: theoretical myth or empirical truth? Results from a meta-analysis. Renew. Sustain. Energy Rev. 20, 504-513.

Viard, V.B., Fu, S., 2015. The Effect of Beijing's Driving Restrictions on Pollution and Economic Activity. J. Public Econ. 125, 98-115.

World Health Organization, 2005. Air Quality Guidelines for Europe. 2nd Edition, WHO Regional Office for Europe, Copenhagen, WHO Regional Publication, European Series No. 91.

Xie, L.Y., Chang, Y.X., Lan, Y., 2019. The Effectiveness and Cost-Benefit Analysis of Clean Heating Program in Beijing. China Environ. Manag. 3, 87-93.

Yang, Y., Luo, L., Song, C., Yin, H., Yang, J., 2018. Spatiotemporal Assessment of $\mathrm{PM}_{2.5}$-Related Economic Losses from Health Impacts during 2014-2016 in China. Int J Environ Res Public Health $15,1278$.

Zhang, Q., Zheng, Y.X., Tong, D., et al., 2019. Drivers of improved PM2.5 air quality in China from 2013 to 2017. Proc. Natl. Acad. Sci. U.S.A. 116, 24463-24469. 
Zhou, B., Zhang, C., Wang, Q., Zhou, D., 2020. Does emission trading lead to carbon leakage in China? Direction and channel identifications. Renewable Sustainable Energy Rev. 132, 110090. 


\section{APPENDIX FOR}

\section{Clean heating and heating poverty:}

\section{A perspective based on cost-benefit analysis}

Table A. 1 Natural gas heating subsidy for each household

\begin{tabular}{|c|c|c|c|c|c|c|c|}
\hline \multirow[b]{2}{*}{ Province } & \multirow[b]{2}{*}{ City } & \multicolumn{2}{|c|}{ Equipment subsidy } & \multicolumn{3}{|c|}{ Natural gas allowance } & \multirow[b]{2}{*}{$\begin{array}{l}\text { Pipeline subsidy } \\
\text { (Yuan/Household) }\end{array}$} \\
\hline & & $\begin{array}{l}\text { Proportion } \\
\quad(\%)\end{array}$ & $\begin{array}{l}\text { Maximum subsidy } \\
\text { (Yuan/Household) }\end{array}$ & $\begin{array}{c}\text { Unit } \\
\text { allowance } \\
\left(\text { Yuan } / \mathrm{m}^{3} \text { ) }\right.\end{array}$ & $\begin{array}{l}\text { Maximum } \\
\text { electricity } \\
\left(\mathrm{m}^{3}\right)\end{array}$ & $\begin{array}{l}\text { Maximum allowance } \\
\text { (Yuan/Household) }\end{array}$ & \\
\hline Beijing & & 90 & 7200 & 1.2 & 2000 & 2400 & 9000 \\
\hline Tianjin & & 75 & 6200 & 1.2 & 1000 & 1200 & 0 \\
\hline \multirow{8}{*}{ Hebei } & Shijiazhuang & 70 & 2700 & 1.4 & 1200 & 1680 & 2900 \\
\hline & Tangshan & 70 & 2700 & 0.8 & 1200 & 960 & 4000 \\
\hline & Baoding & 70 & 2700 & 1 & 1200 & 1200 & 4000 \\
\hline & Langfang & 70 & 2700 & 1 & 1200 & 1200 & 4000 \\
\hline & Cangzhou & 70 & 2700 & 1 & 1200 & 1200 & 2600 \\
\hline & Hengshui & 70 & 2700 & 1 & 1200 & 1200 & 2600 \\
\hline & Handan & 70 & 2700 & 0.8 & 1200 & 960 & 2600 \\
\hline & Xingtai & 70 & 2700 & 1 & 900 & 900 & 0 \\
\hline \multirow{4}{*}{ Shanxi } & Taiyuan & 80 & 6000 & 1.1 & 2182 & 2400 & 3000 \\
\hline & Yangquan & 50 & 2000 & 0.5 & 900 & 450 & 1000 \\
\hline & Changzhi & 70 & 3000 & 1 & 1000 & 1000 & 5000 \\
\hline & Jincheng & 70 & 3500 & 1 & 1000 & 1000 & 0 \\
\hline \multirow{9}{*}{ Shandong } & Jinan & 50 & 2000 & 1 & 1200 & 1200 & 0 \\
\hline & Zibo & 70 & 2700 & 1 & 1200 & 1200 & 0 \\
\hline & Liaocheng & 50 & 5000 & 1 & 1000 & 1000 & 0 \\
\hline & Dezhou & 80 & 4000 & 1 & 1000 & 1000 & 0 \\
\hline & Binzhou & 50 & 2000 & 1 & 1200 & 1200 & 3000 \\
\hline & Jining & 80 & 4000 & 1 & 1000 & 1000 & 0 \\
\hline & Heze & 80 & 4000 & 1 & 1000 & 1000 & 0 \\
\hline & Zhengzhou & 70 & 3500 & 1 & 600 & 600 & 0 \\
\hline & Xinxiang & 70 & 3500 & 1 & 600 & 600 & 0 \\
\hline \multirow{5}{*}{ Henan } & Hebi & 50 & 2500 & 1 & 600 & 600 & 0 \\
\hline & Anyang & 60 & 3500 & 1 & 600 & 600 & 0 \\
\hline & Jiaozuo & 90 & 4500 & 1 & 1000 & 1000 & 0 \\
\hline & Puyang & 70 & 3500 & 1 & 600 & 600 & 0 \\
\hline & Kaifeng & 70 & 2000 & 1 & 900 & 900 & 0 \\
\hline
\end{tabular}


Table A. 2 Electric heating subsidy for each household

\begin{tabular}{|c|c|c|c|c|c|c|}
\hline \multirow[b]{2}{*}{ Province } & \multirow[b]{2}{*}{ City } & \multicolumn{2}{|c|}{ Equipment subsidy } & \multicolumn{3}{|c|}{ Electricity allowance } \\
\hline & & $\begin{array}{l}\text { proportio } \\
\mathrm{n}(\%)\end{array}$ & $\begin{array}{l}\text { Maximum subsidy } \\
\text { (Yuan/Household) }\end{array}$ & $\begin{array}{c}\text { Unit allowance } \\
\text { (Yuan/kwh) }\end{array}$ & $\begin{array}{c}\text { Maximum } \\
\text { electricity }(\mathrm{kwh})\end{array}$ & $\begin{array}{c}\text { Maximum allowance } \\
\text { (Yuan/Household) }\end{array}$ \\
\hline Beijing & & 85 & 12000 & 0.2 & 10000 & 2000 \\
\hline Tianjin & & 85 & 7400 & 0.2 & 8000 & 1600 \\
\hline \multirow{8}{*}{ Hebei } & Shijiazhuang & 85 & 7400 & 0.2 & 10000 & 2000 \\
\hline & Tangshan & 85 & 7400 & 0.2 & 10000 & 2000 \\
\hline & Baoding & 85 & 7400 & 0.2 & 10000 & 2000 \\
\hline & Langfang & 85 & 7400 & 0.2 & 10000 & 2000 \\
\hline & Cangzhou & 85 & 7400 & 0.1 & 10000 & 1000 \\
\hline & Hengshui & 85 & 7400 & 0.2 & 10000 & 2000 \\
\hline & Handan & 85 & 7400 & 0.12 & 10000 & 1200 \\
\hline & Xingtai & 85 & 7400 & 0.12 & 10000 & 1200 \\
\hline \multirow{4}{*}{ Shanxi } & Taiyuan & 85 & 8000 & 0.2 & 12000 & 2400 \\
\hline & Yangquan & 50 & 2500 & 0.1 & 10000 & 1000 \\
\hline & Changzhi & 50 & 2500 & 0.1 & 10000 & 1000 \\
\hline & Jincheng & 70 & 5000 & 0.2 & 6000 & 1200 \\
\hline \multirow{7}{*}{$\begin{array}{l}\text { Shandon } \\
\mathrm{g}\end{array}$} & Jinan & 40 & 2000 & 0.2 & 6000 & 1200 \\
\hline & Zibo & 70 & 5700 & 0.2 & 6000 & 1200 \\
\hline & Liaocheng & 75 & 6500 & 0.1 & 10000 & 1000 \\
\hline & Dezhou & 60 & 4000 & 0.1 & 10000 & 1000 \\
\hline & Binzhou & 75 & 4600 & 0.2 & 6000 & 1200 \\
\hline & Jining & 60 & 4000 & 0.1 & 10000 & 1000 \\
\hline & Heze & 60 & 4000 & 0.1 & 10000 & 1000 \\
\hline \multirow{7}{*}{ Henan } & Zhengzhou & 70 & 3500 & 0.2 & 3000 & 600 \\
\hline & Xinxiang & 70 & 3500 & 0.2 & 2100 & 420 \\
\hline & Hebi & 50 & 2500 & 0.2 & 3000 & 600 \\
\hline & Anyang & 60 & 3500 & 0.2 & 3000 & 600 \\
\hline & Jiaozuo & 75 & 4500 & 0.4 & 2500 & 1000 \\
\hline & Puyang & 70 & 3500 & 0.2 & 3000 & 600 \\
\hline & Kaifeng & 70 & 2000 & 0.3 & 3000 & 900 \\
\hline
\end{tabular}


Table A.3 Robustness check on DID estimation

\begin{tabular}{lcccc}
\hline & $(1)$ & $(2)$ & $(3)$ & $(4)$ \\
\hline Post $\times$ Clean heating & $-7.783^{* * *}$ & $-7.778^{* * *}$ & $-7.777^{* * *}$ & -0.692 \\
& $(2.398)$ & $(2.392)$ & $(2.391)$ & $(10.371)$ \\
Observations & 35090 & 35090 & 33880 & 10285 \\
$\mathrm{R}^{2}$ & 0.321 & 0.232 & 0.232 & 0.378 \\
\hline
\end{tabular}

Note: In model (1) and (2), we select " $2+26$ " cities as the treatment group, other 30 cities without clean heating in Hebei, Shandong, Shanxi and Henan provinces as the control group and estimate the whole effects of clean heating on the concentrations of $\mathrm{PM}_{2.5}$ at city level. Model (1) is the basic model which did not include the control variables. Models (2)-(4) controlled the city-level daily average temperature, daily relative humidity, daily precipitation, daily maximum wind speed, weekend dummy and holiday dummy. Considering Beijing and Tianjin as the municipalities, we drop these two municipalities from the treatment group in model (3) and the results are similar with that in model (2). In model (4), we make the placebo test and restrict the sample to the date before the policy and to redefine the during dummy as a variable taking value 1 after 1th November 2015 and value 0 otherwise, which means to pretend that the policy has taken place in November 2015. We choose this date because it is one year before the actual beginning of the policy, and November are the beginning of winter heating in the Northern China. Except for the implementation of the policy, these two dates have similar external environment. The coefficient of the interaction term in model (4) is not statistically significant, which provide no support for the existence of groupspecific pretreatment trends. Robust standard errors are in the parentheses. Standard errors are clustered at the city level. ${ }^{* * *} p<0.01 ;{ }^{* *} p<0.05 ;{ }^{*} p<0.1$ 


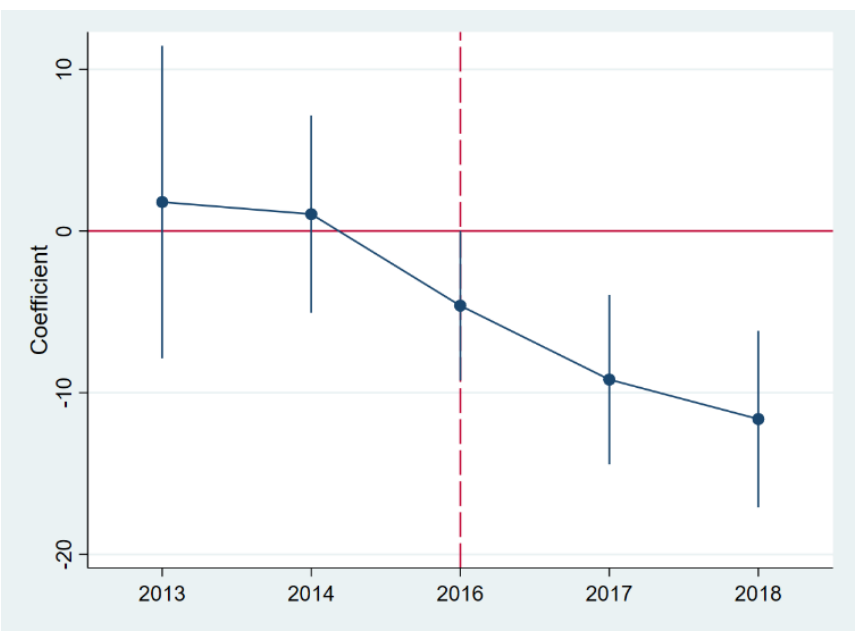

Fig. A 1 Common trend test for difference-in-differences model

Note: We add the interaction terms of each year dummy and the Cleanheating dummy as the main independent variables in difference-in-differences model (5) to verify the hypothesis of common trend. The coefficients of interaction terms of Cleanheating $\times 2013$ and Cleanheating $\times 2014$ are not significant which indicates there is no significant difference between control group and treatment group before the policy. After the implementation of clean heating in November 2016, the coefficients are negative significantly which denotes the clean heating decreased the concentrations of $\mathrm{PM}_{2.5}$. City-level controls include the daily average temperature, daily relative humidity, daily precipitation, maximum wind speed, a dummy variable for whether the day is a weekend day, and a dummy variable for whether the day is national holiday. Standard errors are clustered at the city level. 